\title{
Pharmacological Effects of JTT-551, a Novel Protein Tyrosine Phosphatase 1B Inhibitor, in Diet-Induced Obesity Mice
}

\author{
Makoto Ito, Sumiaki Fukuda, Shohei Sakata, Hisayo Morinaga, and Takeshi Ohta \\ Japan Tobacco Inc., Central Pharmaceutical Research Institute, 1-1 Murasaki-cho, Takatsuki, Osaka 569-1125, Japan \\ Correspondence should be addressed to Takeshi Ohta; takeshi.ota@jt.com
}

Received 24 April 2014; Revised 8 May 2014; Accepted 12 May 2014; Published 29 May 2014

Academic Editor: Norihide Yokoi

Copyright ( 2014 Makoto Ito et al. This is an open access article distributed under the Creative Commons Attribution License, which permits unrestricted use, distribution, and reproduction in any medium, provided the original work is properly cited.

\begin{abstract}
Protein tyrosine phosphatase 1B (PTP1B) is a negative regulator of leptin signaling as well as insulin signaling. JTT-551 is a new PTP1B inhibitor, which is reported to improve glucose metabolism by enhancement of insulin signaling. We have evaluated an antiobesity effect of JTT-551 using diet-induced obesity (DIO) mice. A single administration of JTT-551 was provided to DIO mice with or without leptin, and DIO mice were given food containing JTT-551 for six weeks. A single administration of JTT-551 with leptin treatment enhanced the food inhibition and the signal transducer and activator of transcription 3 (STAT3) phosphorylation in hypothalamus. Moreover, chronic administration of JTT-551 showed an antiobesity effect and an improvement of glucose and lipid metabolism in DIO mice. JTT-551 shows an antiobesity effect possibly by enhancement of leptin signaling and could be useful in the treatment of type 2 diabetes and obesity.
\end{abstract}

\section{Introduction}

The prevalence of obesity continues to increase rapidly worldwide. Body weight is normally maintained within a narrow range by a balance between energy intake and expenditure. When energy intake exceeds energy expenditure, excess energy is stored as triglyceride in adipose tissue, resulting in weight gain. Obesity is an important risk factor for type 2 diabetes, cardiovascular disease, and the metabolic syndrome. Effective antiobesity therapies are urgently needed [1-3].

Leptin, a hormone secreted by adipocytes, decreases body weight both by suppressing appetite and by increasing energy expenditure [4-6]. The brain, particularly the hypothalamus, integrates leptin and various other metabolic signals to regulate energy homeostasis and body weight by controlling both behavior and metabolic responses [7-9]. Genetic deficiency of leptin or functional leptin receptors also results in obesity and obesity-associated metabolic diseases in both animals and humans. Leptin administration decreases body weight and fat mass [10-12]; however, most obese individuals exhibit elevated circulating leptin levels and are less responsive to exogenously administrated leptin, consistent with a leptin resistance $[13,14]$.
Protein tyrosine phosphatase 1B (PTP1B) has been implicated in the negative regulation of the signaling pathway that phosphorylates the tyrosine residue. It is reported that PTP1B knockout mice exhibit increased insulin and leptin sensitivity and are resistant to high-fat diet-induced obesity (DIO) $[15,16]$. DIO rats have a marked increase in PTP1B protein expression in the hypothalamus. It was recently reported that neuronal PTP1B knockout mice are hypersensitive to leptin and have reduced body weight and adiposity and increased energy expenditure $[17,18]$. Treatment of DIO rats with PTP1B antisense oligonucleotide i.c.v. resulted in a decreased food intake, reduced body weight, and reduced adiposity [19]. These results suggest that PTP1B may play a pivotal role in the leptin resistance associated with obesity. Specific PTP1B inhibitors may thus be therapeutically beneficial in obesity as well as in type 2 diabetes.

JTT-551 is a novel PTP1B inhibitor, which is under development as an antidiabetic drug. JTT-551 increases the insulin-stimulated glucose uptake in L6 rat skeletal myoblasts (L6 cells), and single administration enhanced insulin receptor phosphorylation in liver. JTT-551 improves glucose metabolism by enhancement of insulin signaling [20]. 


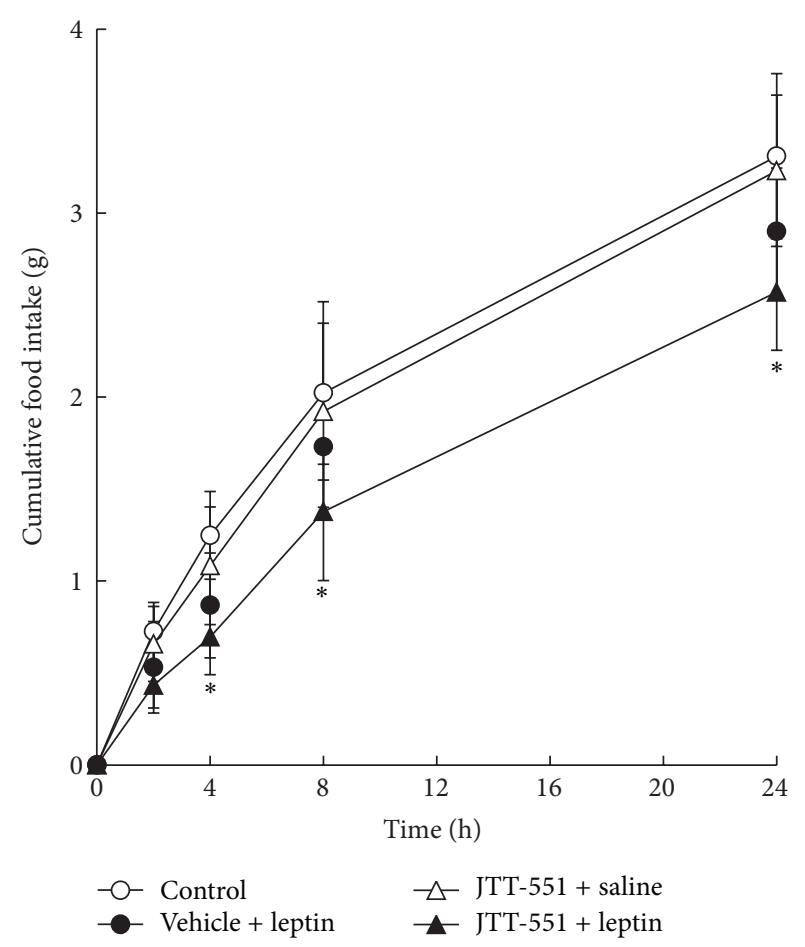

FIGURE 1: Enhancement effect of JTT-551 on leptin suppressed calorie intake in DIO mice. Data represent mean \pm SD $(n=5)$. ${ }^{*} P<0.05$ : significantly different from the control by Dunnett's test (two-tailed).

In the present study, we evaluated the pharmacological profiles, especially the enhancement effect of leptin signaling, of JTT-551 in vivo, and examined whether the compound could be useful as an antiobesity agent.

\section{Materials and Methods}

2.1. Chemicals. JTT-551 was synthesized by Japan Tobacco Inc., Central Pharmaceutical Research Institute (Osaka, Japan).

2.2. Animals. All the experiments received prior approval from the Committee for the Humane Care and Use of Animals of Biological/Pharmacological Research Laboratories, Central Pharmaceutical Research Institute, Japan Tobacco Inc., in accordance with the Japanese Law on Humane Treatment and Management of Animals.

Male six-week-old C57BL/6J mice were purchased from Charles River Japan, Inc. (Yokohama, Japan). Animals were housed in a climate-controlled room (temperature $23 \pm 3^{\circ} \mathrm{C}$, humidity $55 \pm 15 \%$, and $12 \mathrm{~h}$ lighting cycle) and allowed free access to diet and water.

2.3. Acute Effect on DIO Mice. Seven-week-old C57BL/6J mice were provided with 35\% fat diet (Oriental Yeast Co., Osaka, Japan) (Table 1) ad libitum. A single oral administration of JTT-551 $100 \mathrm{mg} / \mathrm{kg}$ was provided to 12 -week-old male DIO mice that had been fasting overnight and then leptin

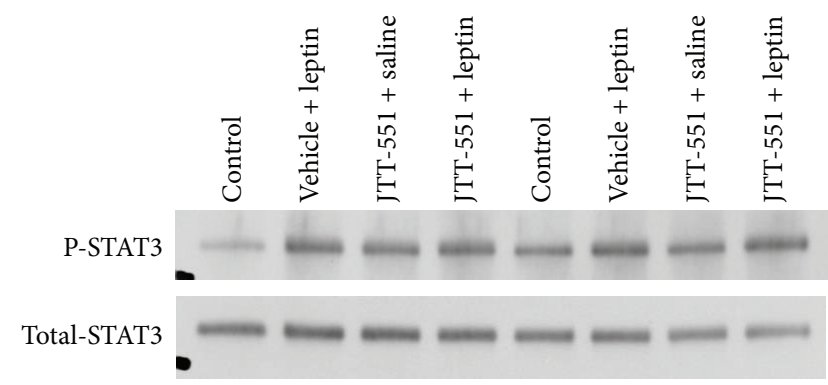

(a)

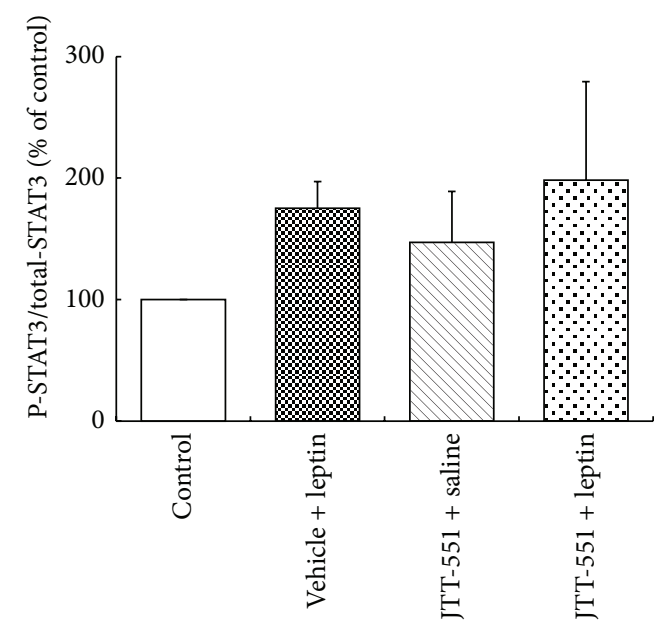

(b)

FIGURE 2: Enhancement effects of JTT-551 on STAT3 phosphorylation in the hypothalamus of DIO mice. The detected bands (typical bands) are shown in (a) and the phosphorylation-STAT3/STAT3 in each group in (b). The intensity of the STAT3 phosphorylation was calculated as the ratio of the density of phosphorylation-STAT3 to the density of STAT3.

solution $10 \mathrm{mg} / \mathrm{kg}$ intraperitoneal administration $1 \mathrm{~h}$ before feeding. Feeding was resumed immediately after dosing and the food was weighed at $2,4,8$, and $24 \mathrm{~h}$. Cumulative food intake was calculated from difference in the weight from that before feeding. Calorie intake was determined under the following provisions: fat, $9 \mathrm{kcal} / \mathrm{g}$; carbohydrate, $4 \mathrm{kcal} / \mathrm{g}$; protein, $4 \mathrm{kcal} / \mathrm{g}$.

Moreover, JTT-551 $100 \mathrm{mg} / \mathrm{kg}$ was provided to 13 -weekold male DIO mice that had been fasting overnight and then leptin solution $10 \mathrm{mg} / \mathrm{kg}$ intraperitoneal administration $1 \mathrm{~h}$ before feeding. The hypothalamus was removed at $2 \mathrm{~h}$ after feeding. The hypothalamus was homogenized and insoluble material was removed by centrifugation. Supernatants were separated using SDS polyacrylamide gel electrophoresis and immunoblotting as previously described [20]. Membranes were probed with antibodies for total and phosphorylated STAT3 (Santa Cruz Biotechnology, CA, USA). Protein phosphorylation was calculated as the ratio of phosphorylated-tototal protein expression.

2.4. Chronic Effect on DIO Mice. Eight-week-old DIO mice were given 10 or $100 \mathrm{mg} / \mathrm{kg}$ food containing JTT-551 for six weeks. Body weight and food consumption were measured 


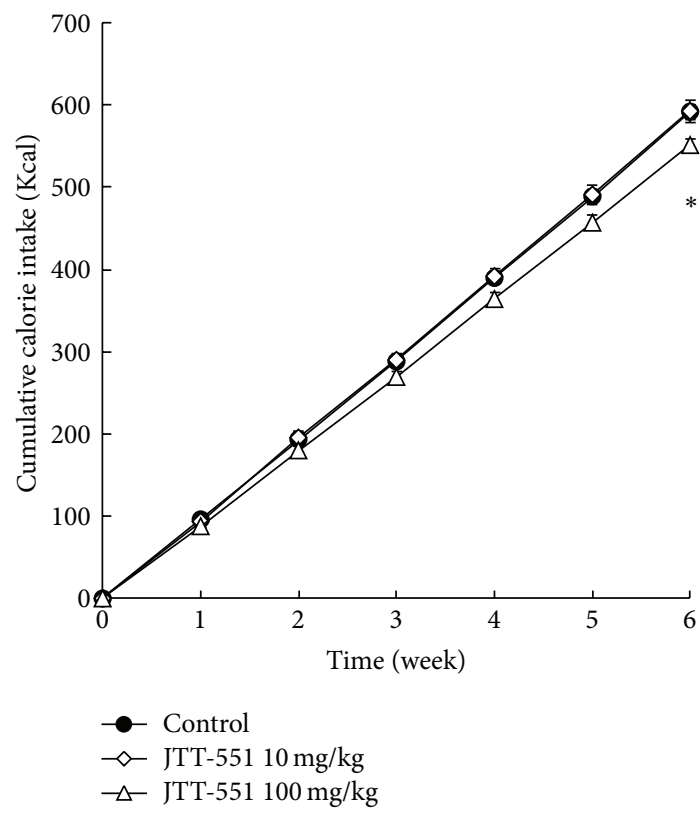

(a)

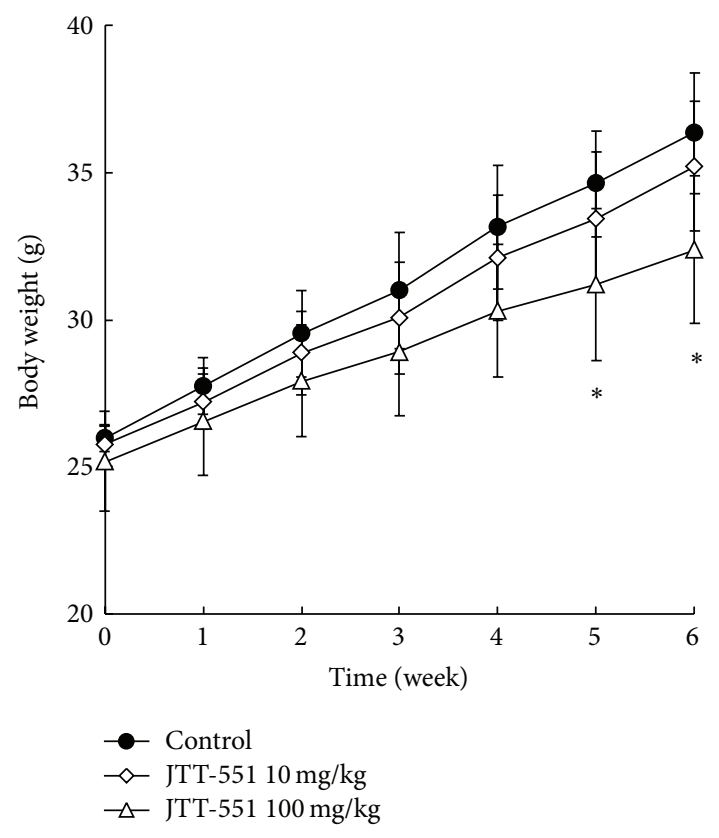

(b)

FIGURE 3: Effect of JTT-551 on cumulative calorie intake and body weight in DIO mice. DIO mice were given $10 \mathrm{or} 100 \mathrm{mg} / \mathrm{kg}$ food containing JTT-551 for six weeks. Data represent mean \pm SD $(n=5) .{ }^{*} P<0.05$ : significantly different from the control by Dunnett's test (two-tailed).

TABLE 1: Composition of the experimental diet.

\begin{tabular}{lc}
\hline$\%(w / w)$ & $35 \%$ fat diet \\
\hline Lard & 35.000 \\
Cornstarch & 7.308 \\
Casein & 28.810 \\
Granulated sugar & 14.410 \\
Cellulose & 7.200 \\
AIN93M mineral mix & 5.040 \\
AIN93 vitamin mix & 1.440 \\
L-cystine & 0.430 \\
Choline bitartrate & 0.360 \\
Butylhydroquinone & 0.002 \\
\hline
\end{tabular}

every week. In fed or fasting DIO mice at six weeks after JTT-551 treatment, blood samples were collected from orbital venous plexus and the blood glucose, triglyceride (TG), and total cholesterol (TC) levels were measured using commercial kits (Roche Diagnostics, Basel, Switzerland) and an automatic analyzer (HITACHI 7170S; Hitachi, Tokyo, Japan). Blood insulin and leptin levels were measured with a rat enzymelinked immunosorbent assay (ELISA) kit (Morinaga Institute of Biological Science, Yokohama, Japan).

2.5. Statistical Analysis. Results of body weight, cumulative calorie intake, and blood chemistry values were expressed as the mean \pm standard deviation (SD). Statistical analysis of mean values was performed using Dunnett's $t$-test (twotailed). Differences were defined as significant at $P<0.05$.

\section{Results}

3.1. Acute Effect on DIO Mice. The results for food intake in DIO mice are shown in Figure 1. In leptin administration group (leptin group), food intake was reduced compared with that in vehicle $(0.5 \% \mathrm{MC})$ administration control group (control group) from $2 \mathrm{~h}$ after feeding. In JTT-551 administration group without leptin treatment (JTT-551 group), food intake was not reduced. In JTT-551 with leptin administration group (JTT-551 + leptin group), food intake was significantly reduced compared with leptin group from $4 \mathrm{~h}$ after feeding.

The results of western blot analysis are shown in Figure 2. The detected bands (typical bands) are shown in Figure 2(a) and the phosphorylated STAT3/STAT3 in each group in Figure 2(b). The STAT3 phosphorylation in the hypothalamus after administration of leptin and/or JTT-551 was increased compared with that in control group. In JTT-551 + leptin group, the STAT3 phosphorylation was more enhanced than in single administration groups.

3.2. Chronic Effect on DIO Mice. Effects of JTT-551 on the cumulative food intake and body weight are shown in Figure 3. In the JTT-551 $100 \mathrm{mg} / \mathrm{kg}$ group, the cumulative calorie intake tended to decrease from two weeks after treatment (control: $193.3 \pm 7.6 \mathrm{Kcal}$ and JTT-551 $100 \mathrm{mg} / \mathrm{kg}$ : $183.8 \pm 14.2 \mathrm{Kcal}$ ) and was significantly decreased from six weeks after treatment (control: $591.8 \pm 21.8 \mathrm{Kcal}$ and JTT-551 $100 \mathrm{mg} / \mathrm{kg}$ : $560.7 \pm 28.6 \mathrm{Kcal}$ ) (Figure 3(a)). The body weight in JTT-551 treatment tended to decrease dose-dependently (control: $36.4 \pm 2.1 \mathrm{~g}$, JTT-551 $10 \mathrm{mg} / \mathrm{kg}: 35.2 \pm 2.2 \mathrm{~g}$, and JTT$551100 \mathrm{mg} / \mathrm{kg}: 32.5 \pm 2.3 \mathrm{~g}$, at six weeks after treatment); the decreases in JTT-551 $100 \mathrm{mg} / \mathrm{kg}$ group were significant from five to six weeks after treatment (Figure 3(b)). 


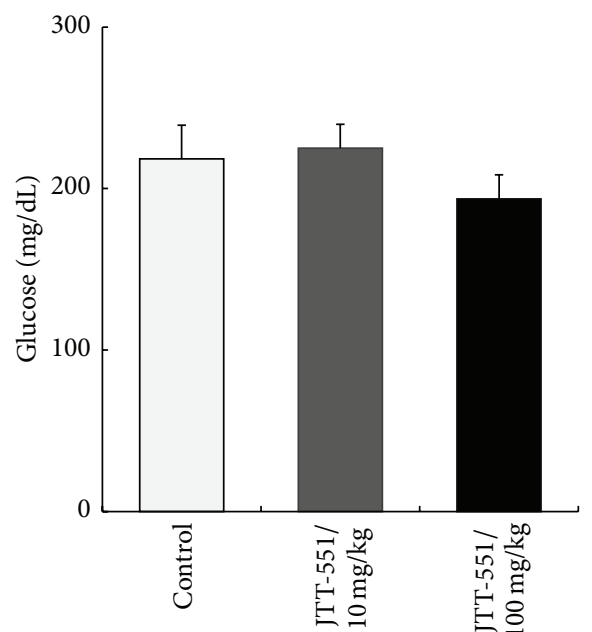

(a)

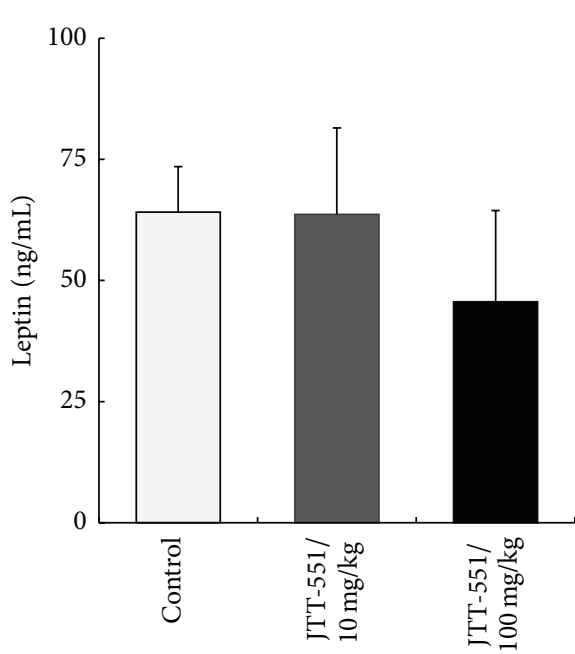

(c)

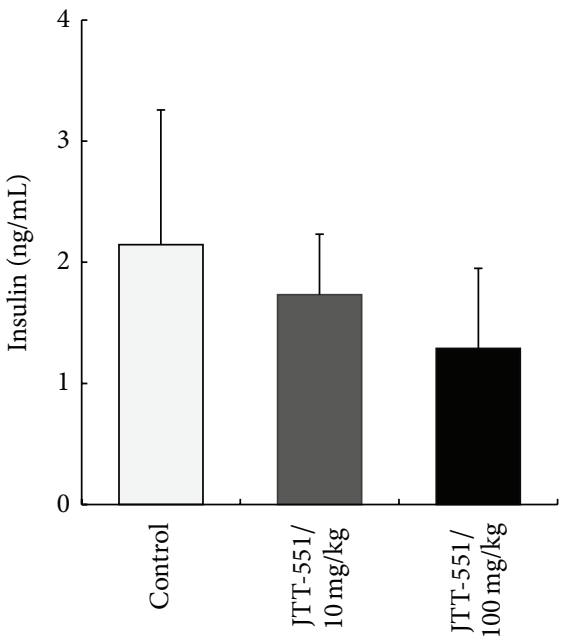

(b)

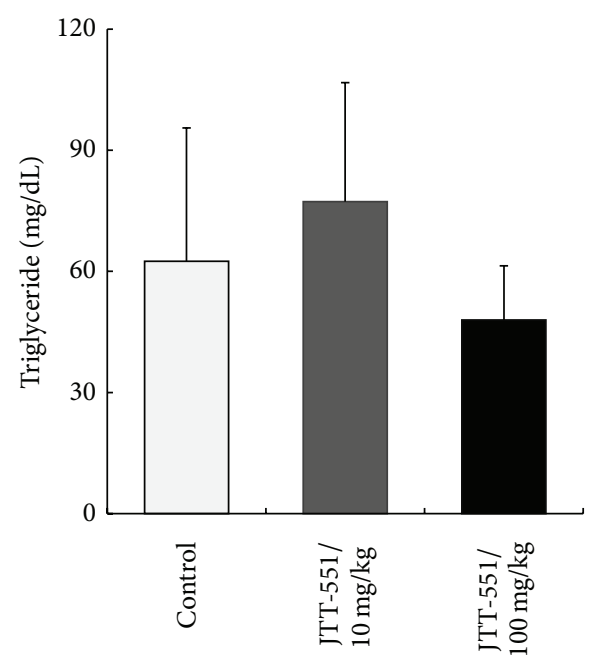

(d)

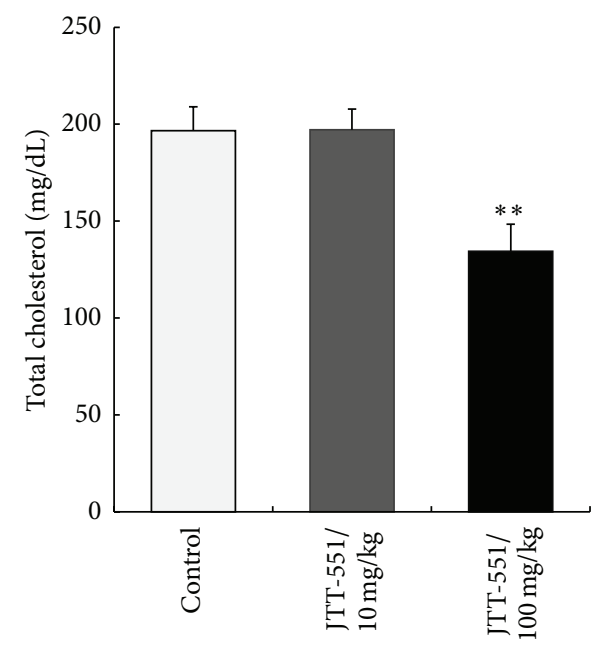

(e)

FIGURE 4: Effects of JTT-551 on blood glucose (a), insulin (b), leptin (c), triglyceride (d), and total cholesterol levels (e) in fed DIO mice. DIO mice were given 10 or $100 \mathrm{mg} / \mathrm{kg}$ food containing JTT-551 for six weeks. Data represent mean $\pm \mathrm{SD}(n=6)$. ${ }^{* *} P<0.01$ : significantly different from the control by Dunnett's test (two-tailed). 


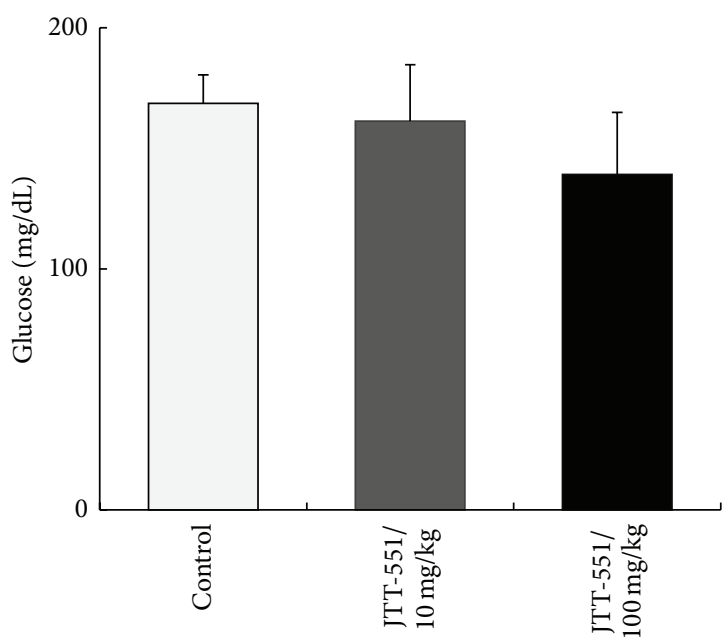

(a)

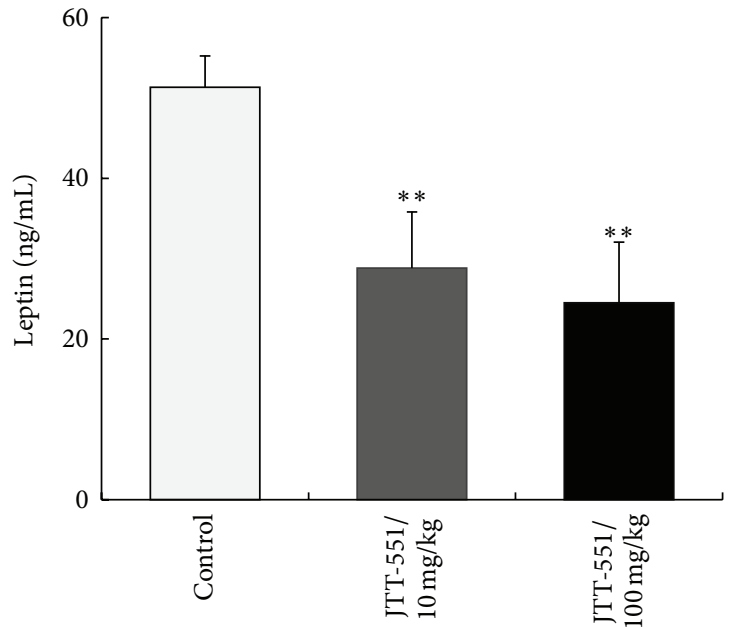

(c)

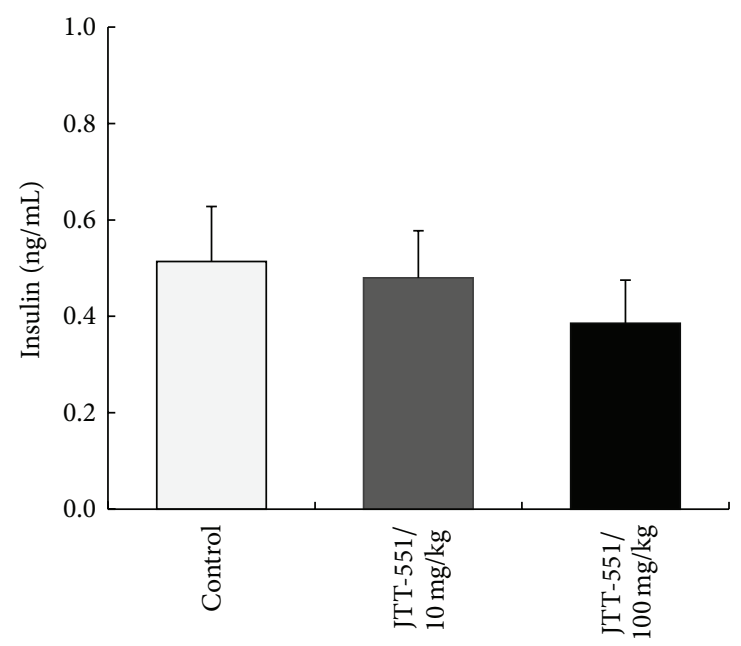

(b)

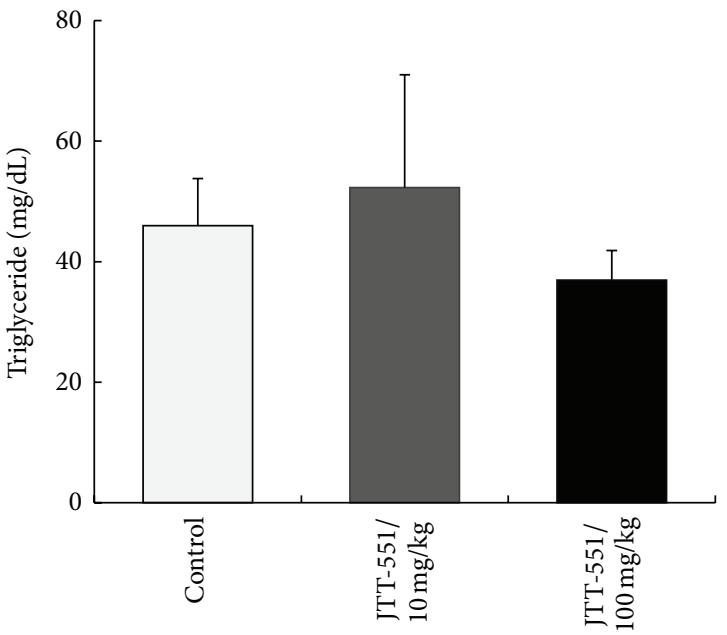

(d)

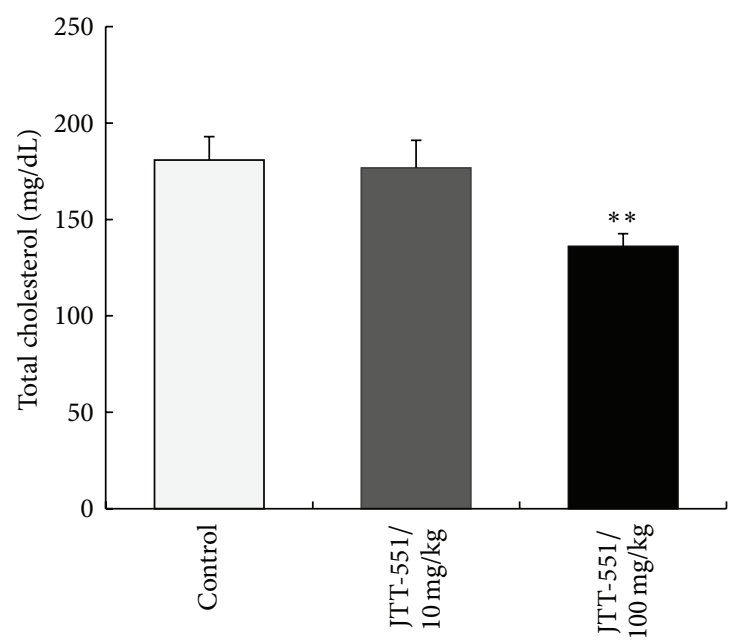

(e)

FIGURE 5: Effects of JTT-551 on blood glucose (a), insulin (b), leptin (c), triglyceride (d), and total cholesterol levels (e) in fasting DIO mice. DIO mice were given 10 or $100 \mathrm{mg} / \mathrm{kg}$ food containing JTT-551 for six weeks. Data represent mean $\pm \operatorname{SD}(n=6) .{ }^{* *} P<0.01$ : significantly different from the control by Dunnett's test (two-tailed). 
Effects of JTT-551 on the blood chemistry values in six weeks after treatment are shown in Figures 4 and 5. The fed blood glucose level was not decreased (Figure 4(a)), but the fasting glucose level at JTT-551 $100 \mathrm{mg} / \mathrm{kg}$ tended to decrease (control: $169 \pm 12 \mathrm{mg} / \mathrm{dL}$ and JTT-551 $100 \mathrm{mg} / \mathrm{kg}$ : $139 \pm$ $26 \mathrm{mg} / \mathrm{dL}$ ) (Figure 5(a)). The insulin levels in both fed and fasting mice tended to decrease, but not significantly (Figures 4(b) and 5(b)). The leptin levels in both fed and fasting mice tended to decrease dose-dependently, and those levels at JTT551 treatment were significantly decreased (control: $51.3 \pm$ $3.9 \mathrm{ng} / \mathrm{mL}$, JTT-551 $10 \mathrm{mg} / \mathrm{kg}: 28.8 \pm 7.0 \mathrm{ng} / \mathrm{mL}$, and JTT-551 $100 \mathrm{mg} / \mathrm{kg}: 24.5 \pm 7.5 \mathrm{ng} / \mathrm{mL}$, in fasting mice) (Figures $4(\mathrm{c})$ and 5(c)). The TG levels in both fed and fasting mice tended to decrease, but not significantly (Figures 4(d) and 5(d)). The TC levels in both fed and fasting mice tended to decrease dosedependently, and those levels at $100 \mathrm{mg} / \mathrm{kg}$ treatment were significantly decreased (control: $196.6 \pm 12.4 \mathrm{mg} / \mathrm{dL}$ and JTT$551100 \mathrm{mg} / \mathrm{kg}: 134.5 \pm 13.9 \mathrm{mg} / \mathrm{dL}$, in fed mice) (Figures 4(e) and $5(\mathrm{e}))$.

\section{Discussion}

PTP1B is a $50-\mathrm{KD}$ cytosolic tyrosine dephosphorylase consisting of 435 amino acids which is ubiquitously expressed in organs throughout the body. It is well known that PTP1B dephosphorylates both phosphorylated insulin receptor (IR) $\beta$ subunit and phosphorylated IR substrate, to negatively regulate insulin signal transmission $[21,22]$. On the other hand, it is reported that PTP1B is concerned with negative regulation of leptin signal transmission, to dephosphorylate phosphorylated STAT3 $[17,18]$. In a recent study, mice lacking the PTP1B were protected from diet-induced obesity and were hypersensitive to leptin. Neuronal PTP1B KO mice especially showed increased leptin signaling in the hypothalamus and had reduced feeding, weight, and adiposity and increased energy expenditure $[15,16]$. This suggests that PTP1B is a key regulator of the leptin signal transmission. PTP1B is a negative regulator of leptin signal, in which the PTP1B inhibits Janus kinase 2 (JAK2)/STAT3 phosphorylation. The inhibition of PTP1B might induce an enhancement of leptin sensitivity. In this study, we investigated an antiobesity effect of JTT-551, which has been developed as a novel PTP1B inhibitor.

Inhibition of food intake in DIO mice was observed in leptin group. In JTT-551 + leptin group, the food intake inhibition was more strongly observed than in leptin group (Figure 1). JTT-551 showed an enhancement of food intake inhibition with leptin treatment. Furthermore, analysis of leptin signal with JTT-551 treatment was examined in DIO mice. Leptin stimulated the phosphorylation of STAT3 in hypothalamus. Also, JTT-551 enhanced the phosphorylation of STAT3 in leptin treatment (Figure 2). The food intake inhibition with JTT-551 might be caused by an enhancement of leptin signal. Leptin signal in the hypothalamus by binding to $\mathrm{Ob}-\mathrm{Rb}$ to activate the tyrosine kinase JAK2 and the activated JAK2 phosphorylates itself and residues Tyr985 and Tyr1138 within the Ob-Rb cytoplasmic tail [23, 24]. Phosphorylated Tyr985 recruits the tyrosine phosphatase Shp2, resulting in leptin-evoked activation of extracellular signal-regulated kinase (Erk). Moreover, Tyr1138 recruits and activates the transcription factor STAT3, and the phosphorylated STAT3 is translocated into the nucleus and transcribed to various leptin target genes. In examination of genetic models, it is reported that leptin injection activated STAT3 in the hypothalamus of ob/ob mice and the wild mice but not $\mathrm{db} / \mathrm{db}$ mice [23]. Since PTP1B dephosphorylates the phosphorylated JAK2 with insulin stimulation and inhibits the phosphorylation of STAT3 $[17,18]$, it is considered that JTT-551 enhanced the leptin signal via an enhancement of phosphorylation of STAT3 in DIO mice.

Obese-related leptin resistance and hyperleptinemia induce promotion of obesity, glucose and lipid metabolic abnormality, and hypertension. Leptin therapy did not show an efficacy for those diseases, and one of the reasons is considered to be a deterioration of leptin signal. Since the blood leptin levels in DIO mice were decreased by JTT-551 treatment (Figures 4(c) and 5(c)), leptin resistance might be improved by an inhibition of PTP1B. Furthermore, chronic administration of JTT-551 showed an antiobesity effect (Figure 3). With an antiobesity effect, long-term treatment with JTT-551 improved lipid disorder and tended to improve glucose metabolic abnormality (Figures 4 and 5). Pharmacological effect of JTT-551 is considered to be induced by the enhancement of insulin and leptin signals. However, the cumulative calorie intake in JTT-551 $100 \mathrm{mg} / \mathrm{kg}$ group was significantly decreased in the late chronic phase, at six weeks after treatment (Figure 3(a)). Since the chronic administration of JTT-551 $100 \mathrm{mg} / \mathrm{kg}$ may act as a feeding deterrent and induce the reduction of body weight, it is necessary to examine carefully the mechanism of an antiobesity effect with JTT-551 treatment in further study.

JTT-551 showed a blood glucose reduction and an improvement of insulin resistance at $10 \mathrm{mg} / \mathrm{kg}$ in ob/ob mice and a decrease of hemoglobin $\mathrm{A}_{1 c}\left(\mathrm{Hb} \mathrm{A}_{1 c}\right)$ level at $30 \mathrm{mg} / \mathrm{kg}$ in $\mathrm{db} / \mathrm{db}$ mice [20]. In our preliminary and present studies, an improvement of leptin signal in hypothalamus of DIO mice was observed at $100 \mathrm{mg} / \mathrm{kg}$ (Figures 1 and 2). An effective dose in leptin signal was higher than that in insulin signal. The reason for this might be a matter of brain penetration of JTT- 551 .

JTT-551, a novel developed PTP1B inhibitor, shows not only an improvement of glucose metabolism but also an antiobesity effect possibly by enhancement of leptin signaling and could be useful in the treatment of type 2 diabetes mellitus and obesity.

\section{Conflict of Interests}

The authors declare that there is no conflict of interests regarding the publication of this paper.

\section{References}

[1] D. W. Haslam and W. P. T. James, “Obesity”, The Lancet, vol. 366, no. 9492, pp. 1197-1209, 2005.

[2] S. M. Haffner, "Abdominal adiposity and cardiometabolic risk: do we have all the answers?" American Journal of Medicine, vol. 120, no. 9, pp. S10-S16, 2007.

[3] S. Colagiuri, "Diabesity: therapeutic options," Diabetes, Obesity and Metabolism, vol. 12, no. 6, pp. 463-473, 2010. 
[4] Y. Zhang, R. Proenca, M. Maffei, M. Barone, L. Leopold, and J. M. Friedman, "Positional cloning of the mouse obese gene and its human homologue," Nature, vol. 372, no. 6505, pp. 425-432, 1994.

[5] J. L. Halaas, K. S. Gajiwala, M. Maffei et al., "Weight-reducing effects of the plasma protein encoded by the obese gene," Science, vol. 269, no. 5223, pp. 543-546, 1995.

[6] J. M. Friedman and J. L. Halaas, "Leptin and the regulation of body weight in mammals," Nature, vol. 395 , no. 6704, pp. 763770,1998 .

[7] L. A. Tartaglia, M. Dembski, X. Weng et al., "Identification and expression cloning of a leptin receptor, OB-R," Cell, vol. 83, no. 7, pp. 1263-1271, 1995.

[8] D. G. Baskin, J. F. Breininger, and M. W. Schwartz, "Leptin receptor mrna identifies a subpopulation of neuropeptide y neurons activated by fasting in rat hypothalamus," Diabetes, vol. 48, no. 4, pp. 828-833, 1999.

[9] G. Brabant, R. Horn, A. Von Zur Mühlen et al., "Free and protein bound leptin are distinct and independently controlled factors in energy regulation," Diabetologia, vol. 43, no. 4, pp. 438-442, 2000.

[10] L. A. Campfield, F. J. Smith, Y. Guisez, R. Devos, and P. Burn, "Recombinant mouse OB protein: evidence for a peripheral signal linking adiposity and central neural networks," Science, vol. 269, no. 5223, pp. 546-549, 1995.

[11] J. L. Halaas, C. Boozer, J. Blair-West, N. Fidahusein, D. A. Denton, and J. M. Friedman, "Physiological response to longterm peripheral and central leptin infusion in lean and obese mice," Proceedings of the National Academy of Sciences of the United States of America, vol. 94, no. 16, pp. 8878-8883, 1997.

[12] I. S. Farooqi, G. Matarese, G. M. Lord et al., "Beneficial effects of leptin on obesity, $\mathrm{T}$ cell hyporesponsiveness, and neuroendocrine/metabolic dysfunction of human congenital leptin deficiency," The Journal of Clinical Investigation, vol. 110, no. 8, pp. 1093-1103, 2002.

[13] J. Licinio, S. Caglayan, M. Ozata et al., "Phenotypic effects of leptin replacement on morbid obesity, diabetes mellitus, hypogonadism, and behavior in leptin-deficient adults," Proceedings of the National Academy of Sciences of the United States of America, vol. 101, no. 13, pp. 4531-4536, 2004.

[14] L. Zabrocka, S. Raczynska, E. Goyke, Z. Sledzinski, and J. Swierczynski, "BMI is the main determinant of the circulating leptin in women after vertical banded gastroplasty," Obesity Research, vol. 12, no. 3, pp. 505-512, 2004.

[15] M. Elchebly, P. Payette, E. Michaliszyn et al., "Increased insulin sensitivity and obesity resistance in mice lacking the protein tyrosine phosphatase-1B gene," Science, vol. 283, no. 5407, pp. 1544-1548, 1999.

[16] L. D. Klaman, O. Boss, O. D. Peroni et al., "Increased energy expenditure, decreased adiposity, and tissue-specific insulin sensitivity in protein-tyrosine phosphatase 1B-deficient mice," Molecular and Cellular Biology, vol. 20, no. 15, pp. 5479-5489, 2000.

[17] A. Cheng, N. Uetani, P. D. Simoncic et al., "Attenuation of leptin action and regulation of obesity by protein tyrosine phosphatase 1B," Developmental Cell, vol. 2, no. 4, pp. 497-503, 2002.

[18] J. M. Zabolotny, K. K. Bence-Hanulec, A. Stricker-Krongrad et al., "PTP1B regulates leptin signal transduction in vivo," Developmental Cell, vol. 2, no. 4, pp. 489-495, 2002.

[19] B. A. Zinker, C. M. Rondinone, J. M. Trevillyan et al., "PTP1B antisense oligonucleotide lowers PTP1B protein, normalizes blood glucose, and improves insulin sensitivity in diabetic mice," Proceedings of the National Academy of Sciences of the United States of America, vol. 99, no. 17, pp. 11357-11362, 2002.

[20] S. Fukuda, T. Ohta, S. Sakata et al., "Pharmacological profiles of a novel protein tyrosine phosphatase 1B inhibitor, JTT-551," Diabetes, Obesity and Metabolism, vol. 12, no. 4, pp. 299-306, 2010.

[21] N. K. Tonks and B. G. Neel, "Combinatorial control of the specificity of protein tyrosine phosphatases," Current Opinion in Cell Biology, vol. 13, no. 2, pp. 182-195, 2001.

[22] X. Wu, V. E. Hardy, J. I. Joseph et al., "Protein-tyrosine phosphatase activity in human adipocytes is strongly correlated with insulin-stimulated glucose uptake and is a target of insulin-induced oxidative inhibition," Metabolism: Clinical and Experimental, vol. 52, no. 6, pp. 705-712, 2003.

[23] C. Vaisse, J. L. Halaas, C. M. Horvath, J. E. Dernell Jr., M. Stoffel, and J. M. Friedman, "Leptin activation of Stat3 in the hypothalamus of wild-type and $o b / o b$ mice but not $d b / d b$ mice," Nature Genetics, vol. 14, no. 1, pp. 95-97, 1996.

[24] H. Higuchi, A. Hasegawa, and T. Yamaguchi, “Transcriptional regulation of neuronal genes and its effect on neural functions: transcriptional regulation of neuropeptide $Y$ gene by leptin and its effect on feeding," Journal of Pharmacological Sciences, vol. 98, no. 3, pp. 225-231, 2005. 


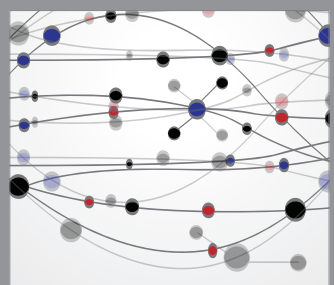

The Scientific World Journal
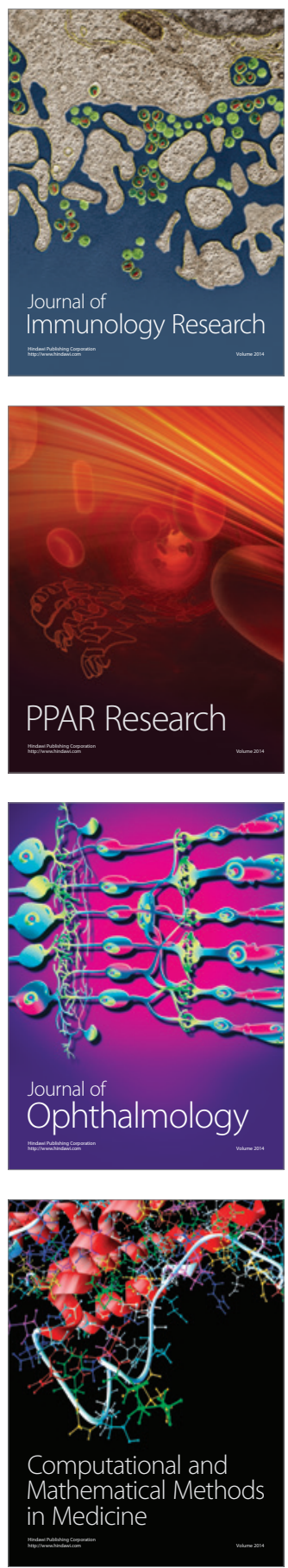

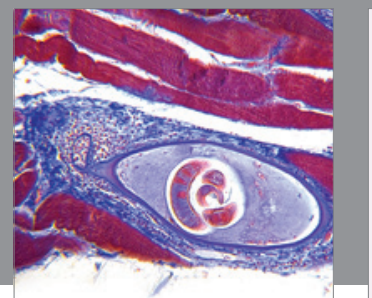

Gastroenterology

Research and Practice
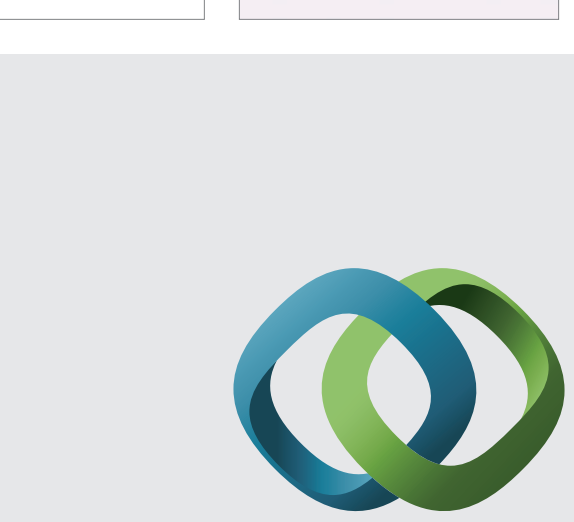

\section{Hindawi}

Submit your manuscripts at

http://www.hindawi.com
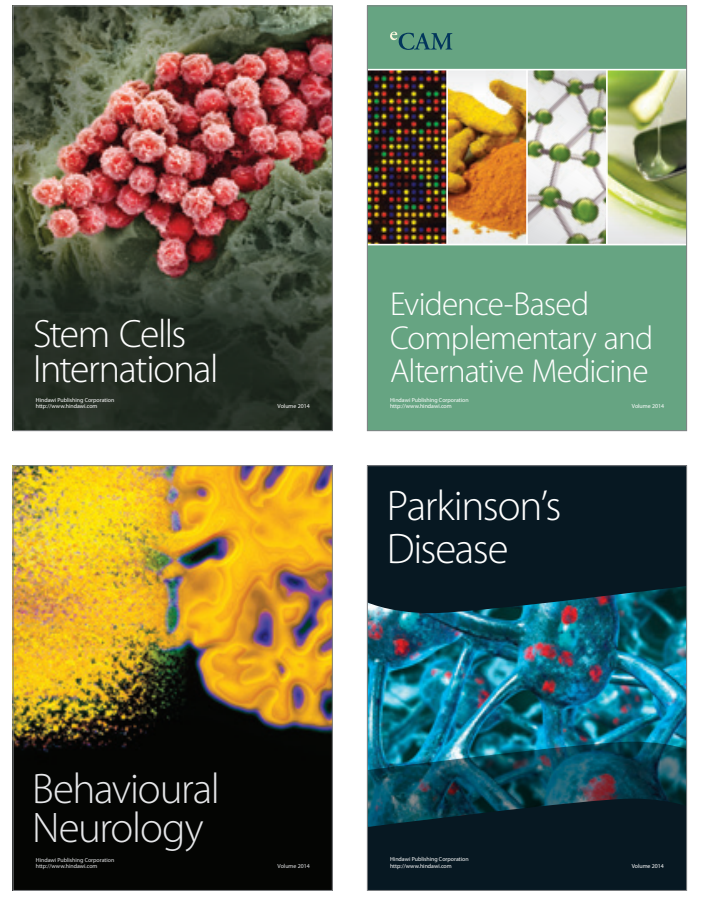
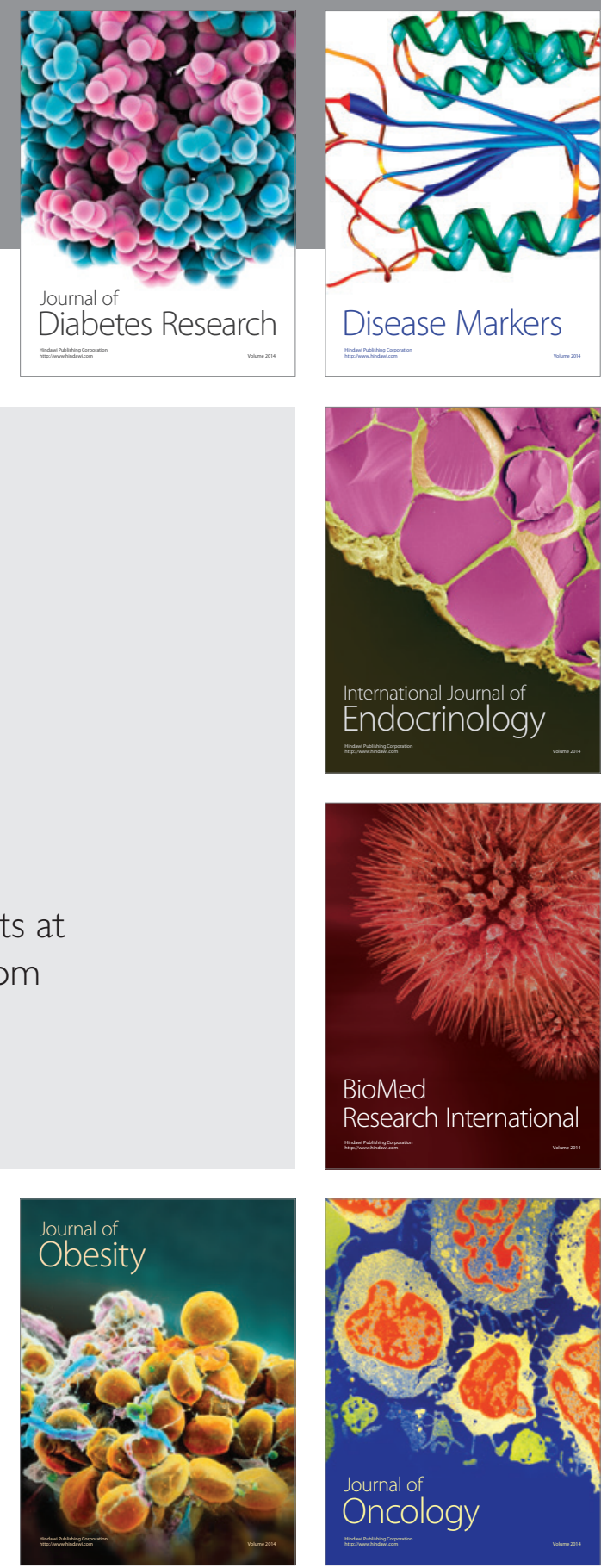

Disease Markers
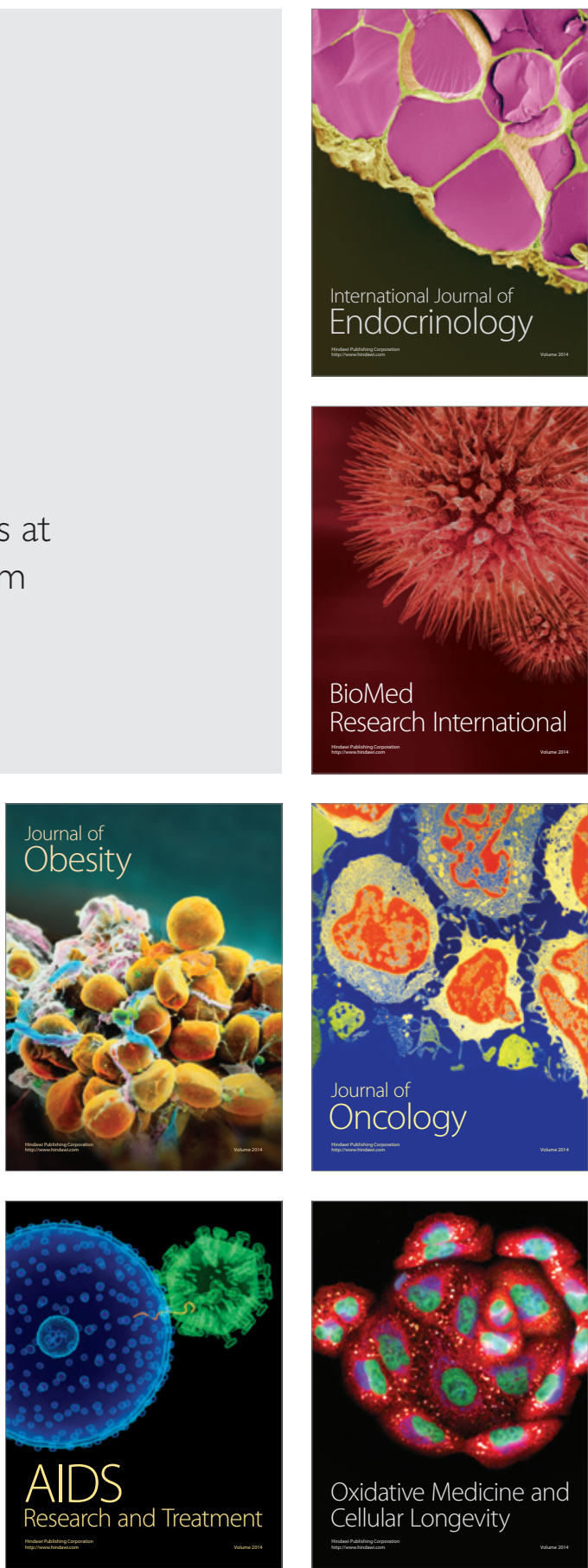